\title{
A Study effect of Substituents $X$ on Methylenecyclopentane and 1- Methylcyclopentene System
}

\author{
Ghassab Al-Mazaideh ${ }^{1}$, Ashraf Al-Msiedeen ${ }^{1}$, Fadi Alakhras ${ }^{2}$, Hammad Aldal'in ${ }^{3}$, Haya Ayyal Salman ${ }^{1}$, \\ Zeinab Al-Itiwi ${ }^{1}$, Khaled Al Khalyfeh ${ }^{4}$, Salim Khalil ${ }^{1}$ \\ 1) Department of Chemistry and Chemical Technology, Faculty of Science, Tafila Technical University, P.O.Box 179, Tafila 66110, Jordan \\ 2) Department of Chemistry, College of Science, Imam Abdulrahman Bin Faisal University, P.O. Box 1982, Dammam 31441, Saudi Arabia \\ 3) Department of Medical Support, Al-Balqa Applied University, Al-Karak University College, Al-Karak, Jordan \\ 4) Department of Chemistry, College of Sciences, Al-Hussein Bin Talal University, Ma'an, Jordan
}

In this study, the geometry optimizations, orbital energies (HOMO-LUMO) and relative stabilities of methylene cyclopentane and 1-methylcyclopentene were investigated by DFT calculations. 1-methylcyclopentene was found to be more stable than methylene cyclopentane isomer with enthalpy value $\mathrm{H}=18.518 \mathrm{~kJ} / \mathrm{mol}$. Also, the effect of substituents $\mathrm{X}$ ( $\mathrm{F}$, OH, $\mathrm{CH}_{3}, \mathrm{NH}_{2}, \mathrm{CN}, \mathrm{NO}_{2}, \mathrm{CHO}$ and $\mathrm{CF}_{3}$ ) also studied on the relative stabilities of these two tautomers. The results showed that the stability of both isomers is increased by all substitutes. Gibbs free energy calculations have been used to find the effect of substituents $X$ on the system.

Keywords: methylene cyclopentane, 1-methylcyclopentene, substituent, tautomer, DFT

\section{Introduction}

Tautomerism is a constitutional isomer, where one or a group of atoms can be moved to provide a new form that differs from initial instability (Moradi et al., 2012). Currently, the system with a transfer proton between the two-tautomer is important in mechanistic chemistry and industrial synthesis (Sway et al., 2004). Methylenecyclopropane/1-methylcyclopropene system (Scheme 1) has been studied by DFT/B3LYP; and it was found that methylenecyclopropane is more stable than 1-methylcyclopropene by $11.535 \mathrm{kcal} / \mathrm{mol}(\mathrm{Khalil}$, 2008). This agreed with a calculated Gibbs free energy, $\Delta \mathrm{G}$ for the system $(\Delta \mathrm{G}=11.615 \mathrm{kcal} / \mathrm{mol})$, which indicates that this system is nonspontaneous; and methylenecyclopropane is more stable than 1-methylcyclopropene. Also, it was found that an increase in the number of substituting fluorine atoms causes a destabilization of methylenecyclopropane.

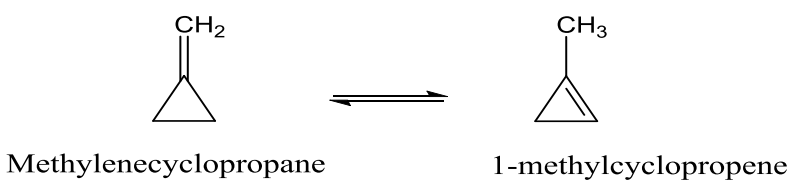

Scheme 1

This system was compared to fluorinated Cyclopropenone Keto-Enol and Fluorinated Methylene cyclopentane/1-Methylcyclopentene system. It was found that an increase in the number of fluorine atoms causes a destabilization of cyclopropenone and methylene cyclopentane (El-Alali et al., 2003). Both experimental data and quantum mechanical calculations indicate that fluorination strongly destabilize the acyclic alkenes and the forward reaction less favorable. Theoretical calculations show that multiple fluorination strongly destabilizes a double bond, but a single fluorine atom stabilizes a double bond by an amount near to methyl group (2-3 kcal/mol) (Lindner et al., 1997; Smart, 1986). 
Parameterized Model number 3 PM3 and DFT (Density Functional Theory) calculations were performed on the methylene cyclobutane, 1methylcyclobutene with different substituents $\mathrm{X}\left(\mathrm{F}, \mathrm{CH}_{3}, \mathrm{NH}_{2}, \mathrm{CN}, \mathrm{NO}_{2}, \mathrm{CHO}\right.$ and $\left.\mathrm{CF}_{3}\right)$ in the gas and aqueous phases. The results show that methylene cyclobutane is more stable than 1-methylcyclobutene in the gas and aqueous phases. Also, it is found that the stability of 1methylcyclobutene increases by all substituents (Al-Mazaideh et al., 2016). DFT is the most accurate method in chemical calculations, where DFT at the B3LYP/ 6-311G basis set level and semiempirical methods (PM3, AM1, and MINDO/3) are applied using G03 on six new substituted Schiff bases derivatives of INHC (N-(3-(phenylidene-allylidene) isonicotino-hydrazide). In addition, it is found that DFT calculations of vibration frequencies and IR absorption intensities for these new INHC Schiff bases derivative molecules give very good assignment values in comparison to the experimental values (Kubba and Abood, 2015). Optimized geometries of stepwise fluorinated methylenecyclopentane and 1-methylcyclopentene are determined by DFT; and it is found that 1-methylcyclopentene is more stable than methylenecyclopentane by $5.612 \mathrm{kcal} / \mathrm{mol}$ (Scheme 2). Perfluorination of 1-methylcyclopentene is found to be present in substantial concentration (Al-Mazaideh et al., 2016). Recently (Wedian and Al-Qudaha, 2016; Al-Msiedeen et al., 2016; Al-Mazaideh et al., 2017; Al-Mazaideh et al., 2016; Al-Mazaideh et al., 2016; Khalil et al., 2016; Al-Mazaideh, 2017; Al-Mazaideh, Al-Quran, 2018), DFT has been applied on the corrosion inhibitors of metals; and very satisfactory results reached.<smiles>C=C1CCCC1</smiles>

Methylenecyclopentane

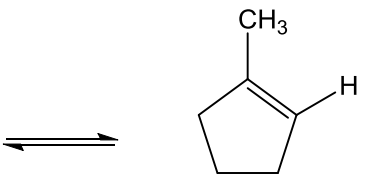

1-methylcyclopentene

\section{Scheme 2}

The aim of this work is to give more theoretical insights to the problem of tautomerism of methylenecyclopentane and 1methylcyclopentene by calculating the effects of substituents $\mathrm{X}\left(\mathrm{F}, \mathrm{OH}, \mathrm{CH}_{3}, \mathrm{NH}_{2}, \mathrm{CN}, \mathrm{NO}_{2}, \mathrm{CHO}\right.$ and $\left.\mathrm{CF}_{3}\right)$ on the relative stabilities of these two tautomers. Gibbs free energy $(\Delta \mathrm{G})$ has been used to calculate and give indications about the spontaneity of the system. Dipole moments and the optimized geometries will be reported for the first time using DFT calculations.

\section{Materials and Methods}

DFT calculations of methylenecyclopentaneand1-methylcyclopentene tautomerism and the effects of substituents $\mathrm{X}\left(\mathrm{F}, \mathrm{OH}, \mathrm{CH}_{3}, \mathrm{NH}_{2}\right.$, $\mathrm{CN}, \mathrm{NO}_{2}, \mathrm{CHO}$ and $\mathrm{CF}_{3}$ ) on the relative stabilities of these two tautomers have been investigated by using the Gaussian 03 package program (Frisch et al., 2003). The geometry and molecular energy of target compounds are completely minimized by DFT at the hybridity level of the three-parameter function of Becke (B3LYP) with 6-31G* $(d, p)$ basis set in G03 program. In this work, the structures of the parent compounds have been designed by using Chem Office 2008 software. The final optimization of the methylenecyclopentane and its counterpart together with different substituents have been calculated and investigated by DFT method which is operated in theory of the levels B3LYP/6-31G*.

\section{Results and Discussion}

All DFT calculations of the structural geometry of Methylenecyclopentane and 1-methylcyclopentene and their derivatives (Figure 1) are carried out using the B3LYP /6-31G* basis set. Bond lengths and angles of all optimized compounds calculated in a gaseous state. These data are given in Tables $\mathbf{1}$ and $\mathbf{2}$. 


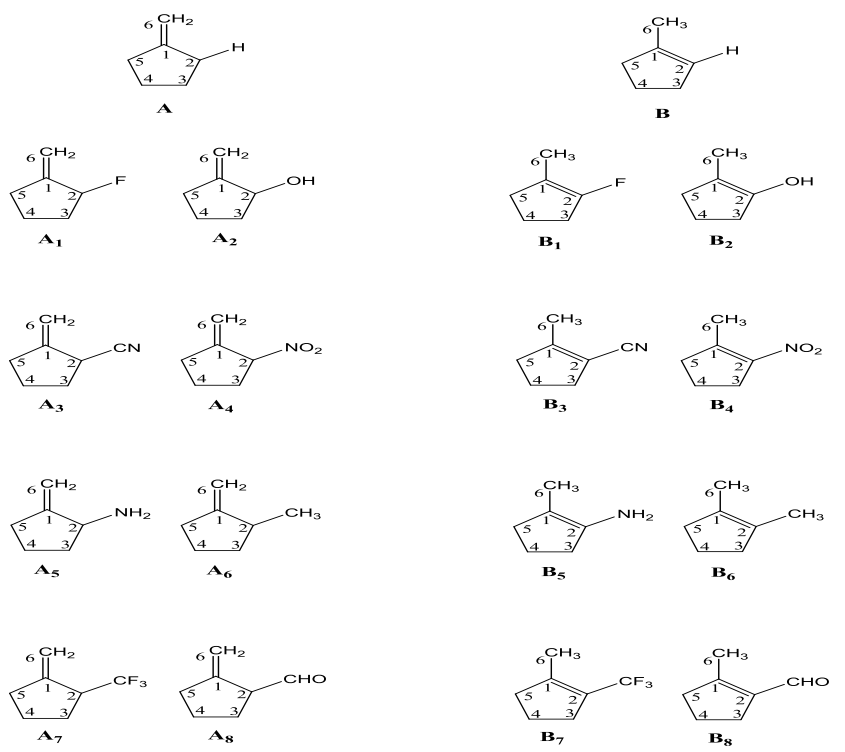

Fig. 1 Molecular structure of substituted methylene cyclopentane (A) and 1-methylcyclopentene (B)

The effect of substituents $\mathrm{X}$ on both parent structures shows that some $\mathrm{C}-\mathrm{C}$ bonds have not been influenced. Methylenecyclopentane has been the most distinction bond length of $\mathrm{C} 1-\mathrm{C} 2$ on molecule $\mathrm{A} 3$ where the maximum difference value is at $0.017 \AA$. . 1-methylcyclopentene has the most distinction bond length of $\mathrm{C} 1-\mathrm{C} 2$ on molecule $\mathrm{B} 8$ where the maximum difference value is at $0.015 \AA$. Thus $\mathrm{C}$-C bond length dissimilarity is not significant for all derivatives of parent compounds. It is clear from Table 1 that there is no variation between bond length in methylene cyclopentane and its substituted derivatives and their counterparts in the 1-methylcyclopentene compounds, except for the bonds $\mathrm{C} 1$ - $\mathrm{C} 6$ and $\mathrm{C} 1$ - $\mathrm{C} 2$ in compound $\mathbf{A}$ and $\mathbf{B}$, where the variation in these bond lengths in all derivatives result from the existence of conjugation.

\subsection{Orbital Energies (HOMO and LUMO) of parent compounds and their derivatives}

Table 1 Calculated bond lengths for methylene cyclopentane / 1-methylcyclopentene and their derivatives

\begin{tabular}{|c|c|c|c|c|c|c|c|c|c|c|}
\hline \multirow[t]{2}{*}{ Molecule } & \multicolumn{10}{|c|}{ Bond distance $(\stackrel{\AA}{\mathbf{A}})$} \\
\hline & & $\mathrm{C} 1-\mathrm{C} 6$ & & $\mathrm{C} 1-\mathrm{C} 2$ & $\mathrm{C} 2-\mathrm{C} 3$ & $\mathrm{C} 3-\mathrm{C} 4$ & $\mathrm{C} 4-\mathrm{C} 5$ & $\mathrm{C} 5-\mathrm{C} 1$ & & $\mathrm{C} 2-\mathrm{X}$ \\
\hline $\mathbf{A}$ & 1.333 & $\mathrm{C} 1=\mathrm{C} 6$ & 1.526 & $\mathrm{C} 1-\mathrm{C} 2$ & 1.543 & 1.540 & 1.543 & 1.526 & 3.336 & C2-H \\
\hline A1 & 1.333 & $\mathrm{C} 1=\mathrm{C} 6$ & 1.517 & $\mathrm{C} 1-\mathrm{C} 2$ & 1.527 & 1.542 & 1.547 & 1.525 & 1.411 & C2-F \\
\hline A2 & 1.335 & $\mathrm{C} 1=\mathrm{C} 6$ & 1.523 & $\mathrm{C} 1-\mathrm{C} 2$ & 1.531 & 1.542 & 1.547 & 1.524 & 1.438 & C2-OH \\
\hline $\mathbf{A 3}$ & 1.331 & $\mathrm{C} 1=\mathrm{C} 6$ & 1.543 & $\mathrm{C} 1-\mathrm{C} 2$ & 1.555 & 1.537 & 1.541 & 1.522 & 1.471 & $\mathrm{C} 2-\mathrm{CN}$ \\
\hline A4 & 1.332 & $\mathrm{C} 1=\mathrm{C} 6$ & 1.532 & $\mathrm{C} 1-\mathrm{C} 2$ & 1.535 & 1.540 & 1.541 & 1.521 & 1.528 & $\mathrm{C} 2-\mathrm{NO}_{2}$ \\
\hline A5 & 1.333 & $\mathrm{C} 1=\mathrm{C} 6$ & 1.532 & $\mathrm{C} 1-\mathrm{C} 2$ & 1.549 & 1.540 & 1.541 & 1.515 & 1.474 & $\mathrm{C} 2-\mathrm{NH}_{2}$ \\
\hline A6 & 1.334 & $\mathrm{C} 1=\mathrm{C} 6$ & 1.532 & $\mathrm{C} 1-\mathrm{C} 2$ & 1.549 & 1.540 & 1.542 & 1.524 & 1.541 & $\mathrm{C} 2-\mathrm{CH}_{3}$ \\
\hline A7 & 1.333 & $\mathrm{C} 1=\mathrm{C} 6$ & 1.534 & $\mathrm{C} 1-\mathrm{C} 2$ & 1.551 & 1.540 & 1.539 & 1.521 & 1.522 & $\mathrm{C} 2-\mathrm{CF}_{3}$ \\
\hline A8 & 1.334 & $\mathrm{C} 1=\mathrm{C} 6$ & 1.539 & $\mathrm{C} 1-\mathrm{C} 2$ & 1.554 & 1.543 & 1.539 & 1.517 & 1.517 & C2-CHO \\
\hline B & 1.499 & C1-C6 & 1.339 & $\mathrm{C} 1=\mathrm{C} 2$ & 1.511 & 1.552 & 1.549 & 1.518 & 3.199 & C2-H \\
\hline B1 & 1.496 & C1-C6 & 1.334 & $\mathrm{C} 1=\mathrm{C} 2$ & 1.500 & 1.551 & 1.557 & 1.515 & 1.351 & C2-F \\
\hline B2 & 1.497 & C1-C6 & 1.341 & $\mathrm{C} 1=\mathrm{C} 2$ & 1.509 & 1.548 & 1.553 & 1.514 & 1.372 & C2-OH \\
\hline B3 & 1.495 & $\mathrm{C} 1-\mathrm{C} 6$ & 1.350 & $\mathrm{C} 1=\mathrm{C} 2$ & 1.521 & 1.549 & 1.548 & 1.513 & 1.425 & $\mathrm{C} 2-\mathrm{CN}$ \\
\hline B4 & 1.495 & C1-C6 & 1.348 & $\mathrm{C} 1=\mathrm{C} 2$ & 1.507 & 1.548 & 1.549 & 1.516 & 1.445 & $\mathrm{C} 2-\mathrm{NO}_{2}$ \\
\hline B5 & 1.499 & $\mathrm{C} 1-\mathrm{C} 6$ & 1.348 & $\mathrm{C} 1=\mathrm{C} 2$ & 1.513 & 1.545 & 1.549 & 1.515 & 1.400 & $\mathrm{C} 2-\mathrm{NH}_{2}$ \\
\hline B6 & 1.500 & $\mathrm{C} 1-\mathrm{C} 6$ & 1.345 & $\mathrm{C} 1=\mathrm{C} 2$ & 1.518 & 1.547 & 1.547 & 1.518 & 1.500 & $\mathrm{C} 2-\mathrm{CH}_{3}$ \\
\hline B7 & 1.499 & C1-C6 & 1.344 & $\mathrm{C} 1=\mathrm{C} 2$ & 1.518 & 1.547 & 1.545 & 1.519 & 1.492 & $\mathrm{C} 2-\mathrm{CF}_{3}$ \\
\hline B8 & 1.498 & C1-C6 & 1.354 & $\mathrm{C} 1=\mathrm{C} 2$ & 1.515 & 1.548 & 1.548 & 1.515 & 1.463 & C2-CHO \\
\hline
\end{tabular}


In Table 2, the effect of substituent $\mathrm{X}$ on bond angle has no significance. On the other hand, in all derivatives of both parent compounds, a fluctuation exists among many bond angles that go from 0.01 degrees to 1.79 degrees for methylenecyclopentane compounds; and from 0.03 degrees to 3.57 degrees for 1-methylcyclopentene. For the methylenecyclopentane compounds, the bond angle C6-C1-C5 on molecule A4 has the maximum value of 127.55 degrees. For 1-methylcyclopentene compounds the bond angle C6-C1-C2 on molecule B7 has the maximum value of 130.84 degrees. In addition, C3-C4-C5 and C2-C3-C4 bond angles on molecules A5 and B1 are found to have the minimum value at 102.92 and 101.29 degrees compared to other compounds.

Table 2 Calculated bond angle for methylenecyclopentane / 1-methylcyclopentene and their derivatives

\begin{tabular}{|c|c|c|c|c|c|c|c|}
\hline \multirow[t]{2}{*}{ Molecule } & \multicolumn{7}{|c|}{ Bond angle in degree $\left(^{\circ}\right)$} \\
\hline & $\mathrm{C} 6-\mathrm{C} 1-\mathrm{C} 2$ & C6-C1-C5 & $\mathrm{C} 2-\mathrm{C} 1-\mathrm{C} 5$ & $\mathrm{C} 1-\mathrm{C} 2-\mathrm{C} 3$ & $\mathrm{C} 2-\mathrm{C} 3-\mathrm{C} 4$ & $\mathrm{C} 3-\mathrm{C} 4-\mathrm{C} 5$ & $\mathrm{C} 4-\mathrm{C} 5-\mathrm{C} 1$ \\
\hline $\mathbf{A}$ & 125.78 & 125.78 & 108.44 & 104.70 & 103.48 & 103.48 & 104.70 \\
\hline A1 & 124.18 & 127.30 & 108.51 & 104.27 & 103.11 & 103.69 & 104.73 \\
\hline A2 & 124.15 & 127.19 & 108.65 & 103.73 & 103.37 & 103.87 & 104.90 \\
\hline A3 & 124.43 & 127.08 & 108.49 & 103.94 & 103.69 & 103.40 & 104.76 \\
\hline A4 & 124.14 & 127.55 & 108.30 & 105.38 & 104.89 & 103.47 & 104.56 \\
\hline A5 & 124.73 & 126.40 & 108.79 & 104.48 & 105.24 & 102.92 & 103.28 \\
\hline A6 & 125.27 & 125.60 & 109.13 & 103.67 & 104.31 & 103.23 & 104.66 \\
\hline A7 & 125.24 & 126.02 & 108.74 & 104.59 & 104.70 & 103.47 & 104.67 \\
\hline A8 & 124.39 & 126.82 & 108.73 & 104.61 & 105.27 & 103.52 & 103.83 \\
\hline B & 127.27 & 121.85 & 110.83 & 112.84 & 102.87 & 105.28 & 103.70 \\
\hline B1 & 127.04 & 124.06 & 108.85 & 115.93 & 101.29 & 105.92 & 104.22 \\
\hline B2 & 126.72 & 123.29 & 109.90 & 113.80 & 102.28 & 105.34 & 103.95 \\
\hline B3 & 127.37 & 122.33 & 110.27 & 112.72 & 102.51 & 105.31 & 104.14 \\
\hline B4 & 130.58 & 120.81 & 108.57 & 114.62 & 101.79 & 105.20 & 104.77 \\
\hline B5 & 127.56 & 121.76 & 110.55 & 112.28 & 103.02 & 104.95 & 103.63 \\
\hline B6 & 128.43 & 120.15 & 111.38 & 111.38 & 103.82 & 104.80 & 103.82 \\
\hline B7 & 130.84 & 119.20 & 109.92 & 112.78 & 102.84 & 104.80 & 104.34 \\
\hline B8 & 129.10 & 120.34 & 110.52 & 112.10 & 103.16 & 104.94 & 104.02 \\
\hline
\end{tabular}

The introduction of substituents into methylene cyclopentane and 1-methylcyclopentene slightly affects their orbital energies (HOMO and LUMO) compared to parent compounds. In the case of methylene cyclopentane derivatives (Table 3), substitution causes a decrease in the energy gaps $\left(\mathrm{E}_{\mathrm{g}}\right)$, suggesting consequently a decrease in the stability of these compounds. An exception is for the substituent $\mathrm{CF}_{3}$, which causes a little increase in $\mathrm{E}_{\mathrm{g}}$.

Similarly, different substituents of 1-methylcyclopentene cause a decrease in $\mathrm{E}_{\mathrm{g}}$ except for the case of structure B1. The introduced $\mathrm{F}$ atom results in a slight increase in $\mathrm{E}_{\mathrm{g}}$. In general, the change in $\mathrm{E}_{\mathrm{g}}$ for all investigated structures is not significant in energy gaps for all substituents. $\mathrm{E}_{\mathrm{g}}$ value can be calculated by $\mathrm{E}_{\text {Hомо }}-\mathrm{E}_{\mathrm{LUMO}}$ for the investigated compounds. The $\mathrm{E}_{\mathrm{g}}$ value for methylene cyclopentane was found to be $6.947 \mathrm{eV}$ compared to $7.086 \mathrm{eV}$ for 1-methylcyclopentene. This indicates that methylene cyclopentane is more stable than 1methylcyclopentene by $0.139 \mathrm{eV}$.

$E_{g}$ values can be used to investigate and show the effect of substituents on the stability of parent compounds. $E_{g}$ values are given in Table $\mathbf{3}$ for all compounds. According to these calculations, the substituents $\mathrm{X}$ increase the stability of 1-methylcyclopenteneby, where the differences in $\mathrm{E}_{\mathrm{g}}$ are greater than in the derivatives of methylenecyclopentane except in the case of adding of fluorine $(\mathrm{F})$. B1 has greater $\mathrm{E}_{\mathrm{g}}$ $(7.097 \mathrm{eV})$ than $\mathrm{A} 1(6.900 \mathrm{eV})$ by $0.197 \mathrm{eV}$. As a result, the effect of substituent X on the stability of methylenecyclopentane according to $\mathrm{E}_{\mathrm{g}}$ values is arranged as follows:

\section{$\mathrm{OH}<\mathrm{CH}_{3}<\mathrm{CF}_{3}<\mathrm{F}<\mathrm{CN}<\mathrm{NH}_{2}<\mathrm{CHO}<\mathrm{NO}_{2}$}

Their effect on the stability of 1-methylcyclopentene is arranged as follows:

$$
\mathrm{F}<\mathrm{CH}_{3}<\mathrm{CF}_{3}<\mathrm{OH}<\mathrm{NH}_{2}<\mathrm{CN}<\mathrm{CHO}<\mathrm{NO}_{2}
$$


Table 3 Calculated orbital energies (HOMO and LUMO, in $\mathrm{eV}$ ) of methylenecyclopentane / 1-methylcyclopentene and their derivatives

\begin{tabular}{ccccc}
\hline Compound & HOMO & LUMO & $\boldsymbol{E}_{\mathbf{g}}$ & $\boldsymbol{\mu}(\mathbf{D})$ \\
\hline A & -6.3475 & 0.5999 & 6.9474 & 0.59 \\
A1 & -6.9251 & -0.0243 & 6.9008 & 1.74 \\
A2 & -6.7656 & 0.1809 & 6.9465 & 1.29 \\
A3 & -7.1002 & -0.2078 & 6.8924 & 4.13 \\
A4 & -7.1719 & -1.7287 & 5.4432 & 3.73 \\
A5 & -6.1721 & 0.4716 & 6.6437 & 1.18 \\
A6 & -6.3775 & 0.5680 & 6.9455 & 0.51 \\
A7 & -6.8704 & 0.1026 & 6.9730 & 2.20 \\
A8 & -6.5462 & -0.5762 & 5.9700 & 3.14 \\
B & -6.0755 & 1.0108 & 7.0863 & 0.23 \\
B1 & -6.0041 & 1.0934 & 7.0975 & 1.38 \\
B2 & -5.3363 & 1.4465 & 6.7828 & 1.65 \\
B3 & -6.7566 & -0.8872 & 5.8694 & 4.60 \\
B4 & -7.1802 & -2.1280 & 5.0522 & 4.76 \\
B5 & -4.9526 & 1.5278 & 6.4804 & 1.33 \\
B6 & -5.8312 & 1.0793 & 6.9105 & 0.14 \\
B7 & -6.7961 & -0.0037 & 6.7924 & 2.68 \\
B8 & -6.5829 & -1.3549 & 5.2280 & 3.87 \\
\hline & & & &
\end{tabular}

Table 4 Calculated entropy S, enthalpy $\mathrm{H}$ and Gibbs free energy of methylenecyclopentane /1-methylcyclopentene and their derivatives

\begin{tabular}{cccc}
\hline Compound & $\begin{array}{c}\mathbf{H}^{\circ} \\
(\mathbf{k J} / \mathbf{m o l})\end{array}$ & $\begin{array}{c}\mathbf{S}^{\circ} \\
(\mathbf{J} / \mathbf{m o l} \mathbf{K})\end{array}$ & $\begin{array}{c}\mathbf{G}^{\circ} \\
(\mathbf{k J} / \mathbf{m o l})\end{array}$ \\
\hline A & $\mathbf{- 6 1 5 6 5 0 . 8 8}$ & $\mathbf{3 0 4 . 0 0}$ & $\mathbf{- 6 1 5 7 4 1 . 5 2}$ \\
A1 & -876200.13 & 326.66 & -876297.53 \\
A2 & -813097.42 & 331.85 & -813196.37 \\
A3 & -857820.32 & 341.18 & -857922.04 \\
A4 & -1152555.24 & 353.43 & -1152660.60 \\
A5 & -760899.01 & 333.41 & -760998.41 \\
A6 & -718791.87 & 336.13 & -718892.09 \\
A7 & -1500527.70 & 370.00 & -1500638.01 \\
A8 & -913131.51 & 345.97 & -913234.66 \\
B & $-\mathbf{6 1 5 6 6 9 . 4 0}$ & $\mathbf{3 1 7 . 0 3}$ & $-\mathbf{6 1 5 7 6 3 . 9 2}$ \\
B1 & -876226.56 & 335.41 & -876327.35 \\
B2 & -813133.32 & 341.78 & -813235.22 \\
B3 & -857869.89 & 349.73 & -857974.16 \\
B4 & -1152581.90 & 362.10 & -1152689.93 \\
B5 & -760952.99 & 340.95 & -761054.65 \\
B6 & -718825.69 & 344.67 & -718928.45 \\
B7 & -1500546.30 & 380.10 & -1500659.66 \\
B8 & -913178.76 & 354.07 & -913284.33 \\
\hline & & & \\
\hline
\end{tabular}

\subsection{Dipole Moment of parent compounds and their derivatives}

The introduction of substituent $\mathrm{X}\left(\mathrm{F}, \mathrm{OH}, \mathrm{CH}_{3}, \mathrm{NH}_{2}, \mathrm{CN}, \mathrm{NO}_{2}, \mathrm{CHO}\right.$ and $\left.\mathrm{CF}_{3}\right)$ into methylene cyclopentane and 1-methylcyclopentene counterpart has also affected their dipole moment as compared to the parent compounds. This change in dipole moment is attributed to the change in the structural parameters and electronic structure of these derivatives. Table 3 shows a change in dipole moments for these compounds, where the dipole moment slightly decreases in the case of $\mathrm{CH}_{3}$ from 0.59 Debye for parent compound to $0.51 \mathrm{Debye}$ for $\mathrm{CH}_{3}$ compound. Increases also occur for the rest of substituents. All substituents for 1-methylcyclopentene shows increasing in the dipole moment values except in the case of $\mathrm{CH}_{3}$ (0.14 Debye) compared to its parent compound (0.23 Debye).

\subsection{Thermodynamic calculation of parent compounds and their derivatives:}

\subsubsection{Parent compound:}

Based on Table 4, the enthalpy of 1-methylcyclopentene B is lower than methylenecyclopentane A (Scheme 2), suggesting that B is more stable than A by 0.007053 Hartrees $(18.518 \mathrm{~kJ} / \mathrm{mol})$. Moreover, substituents X increased the stability of compound B as compared to A. This is confirmed by thermodynamic calculations (Table 5), that showed a negative Gibbs free energy $\left(\Delta \mathrm{G}_{\mathrm{r}}{ }^{\circ}=-22.401 \mathrm{~kJ} / \mathrm{mol}\right)$. They further indicate that 1-methylcyclopentene (B) is more stable than methylenecyclopentane A. This value of $\Delta \mathrm{G}_{\mathrm{r}}^{\circ}\left(-22.401 \mathrm{~kJ} / \mathrm{mol}^{\circ}\right)$ is less than that of methylenecyclopropane $\left(\Delta \mathrm{G}_{\mathrm{r}}^{\circ}=48.597 \mathrm{~kJ} / \mathrm{mol}\right)$ and methylenecyclopentane $\left(\Delta \mathrm{G}_{\mathrm{r}}{ }^{\circ}=27.719 \mathrm{~kJ} / \mathrm{mol}\right)($ Al-Mazaideh et al., 2016) tautomerism. This result has been found due to lowering in the ring strain of the 1-methylcyclopentene (five-member ring) with respect to three and four-member rings. Stabilization of 1-methylcyclopentene agrees with the reported study on methylenecyclopentane / 1methycyclopentene system (Al-Mazaideh et al., 2016). 
Table 5 Gibbs free energy $(\Delta \mathrm{G})$ of substituted methylenecyclopentane and 1-methylcyclopentene and their derivatives

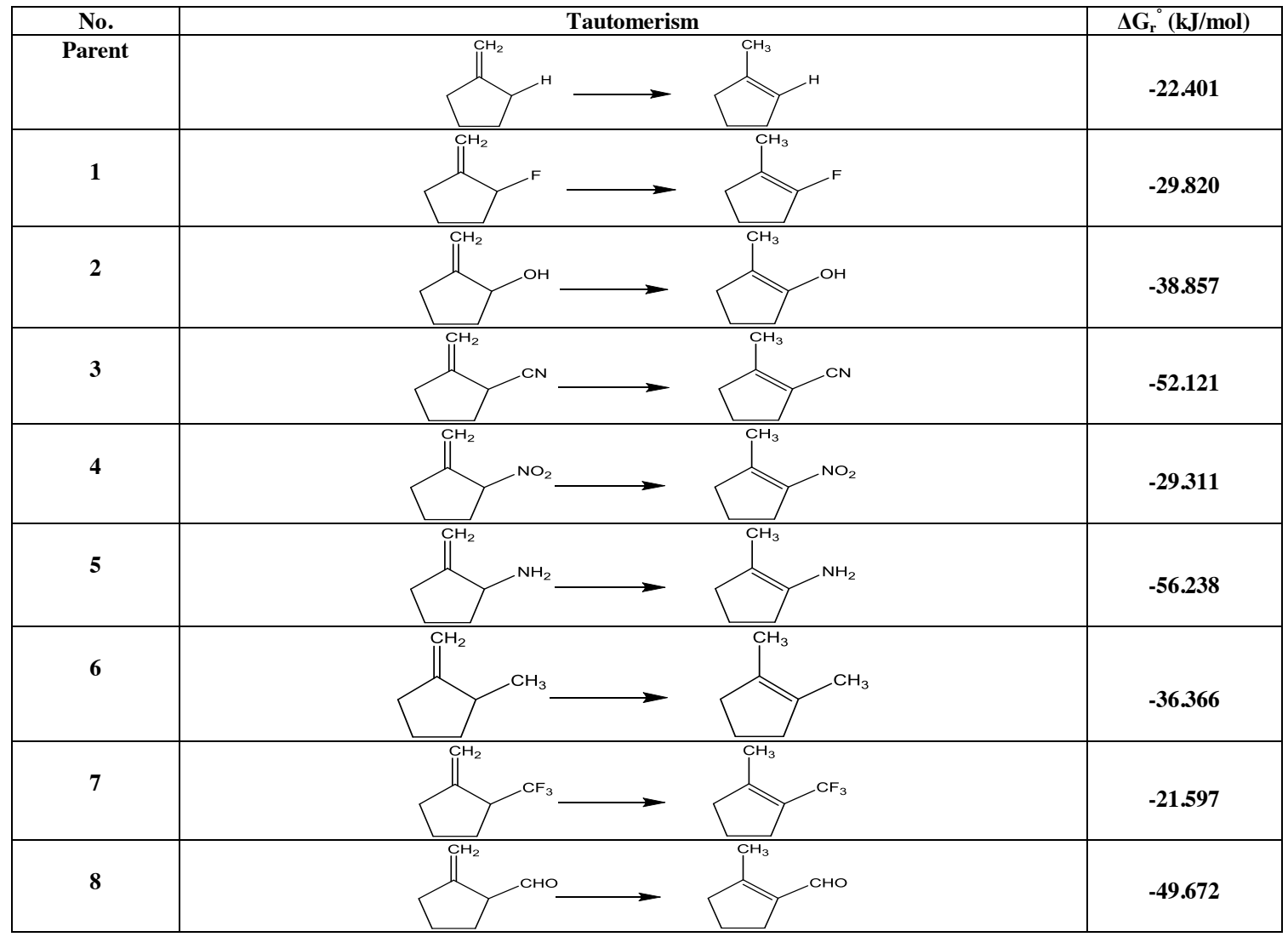

\subsubsection{Effect of substituents}

Introduction of the substituents on the methylenecyclopentane and 1-methylcyclopentene system shows that a negative value of $\Delta \mathrm{G}_{\mathrm{r}}{ }^{\circ}$ can be obtained for all reactions (Table 5). The calculated values are less than those of methylenecyclopentane and 1-methylcyclopentene system. They indicate a spontaneous reaction as substitution increases the stability of 1-methylcyclopentene as compared to methylenecyclopentane. This conclusion is supported with smaller enthalpy values of all 1-methylcyclopentene substituents compared to methylenecyclopentane substituents (Table 4).

\section{Conclusions}

The present study has investigated the effects of substituents $\mathrm{X}\left(\mathrm{F}, \mathrm{OH}, \mathrm{CH}_{3}, \mathrm{NH}_{2}, \mathrm{CN}, \mathrm{NO}_{2}, \mathrm{CHO}\right.$ and $\left.\mathrm{CF}_{3}\right)$ on methylenecyclopentane and 1-methylcyclopentene system. The results of DFT method used in this study show that the 1-methylcyclopentene is more stable than methylenecyclopentane by $18.518 \mathrm{~kJ} / \mathrm{mol}$. The variation between bonds length of methylenecyclopentane compounds and their counterparts in the 1-methylcyclopentene compounds is due to conjugation for both $\mathrm{C} 1-\mathrm{C} 6$ and $\mathrm{C} 1-\mathrm{C} 2$. Yet, the other bond lengths have no variation. In all derivatives of both parent compounds, a fluctuation exists among many bond angles. All substituents have been found to influence on methylenecyclopentane and 1-methylcyclopentene by directing the reaction forward to products and stabilizing the 1-methylcyclopentene as explained by thermodynamic calculations. 


\section{Nomenclature}

$\begin{array}{lll}\mathbf{E}_{\text {Hомо }} & =\text { Energy of highest occupied molecule orbital } & {[\mathrm{eV}]} \\ \mathbf{E}_{\mathbf{L U M O}} & =\text { Energy of lowest un-occupied molecular orbital } & {[\mathrm{eV}]} \\ \boldsymbol{\Delta} \mathbf{H} & =\text { Enthalpy } & {[\mathrm{kJ} / \mathrm{mol}]} \\ \mathbf{D F T} & =\text { Density Functional Theory } & {[-]} \\ \mathbf{B 3 L Y P} & =\text { Becke, 3-parameter, Lee-Yang-Parr } & {[-]} \\ \Delta \mathbf{G} & =\text { Gibbs free energy } & {[\mathrm{kJ} / \mathrm{mol}]} \\ \text { PM3 } & =\text { Parameterized Model number 3 } & {[-]} \\ \text { AM1 } & =\text { Austin Model 1 } & {[-]} \\ \text { MINDO } & =\text { Modified Intermediate Neglect of Differential Overlap } & {[-]} \\ \mathbf{G 0 3} & =\text { Gaussian 2003 } & {[-]} \\ \mathbf{E} & =\text { Energy gap } & {[\mathrm{eV}]} \\ \boldsymbol{\mu} & =\text { Dipole moment } & {[\mathrm{Debye}, \mathrm{D}]} \\ \mathbf{S} & =\text { Entropy } & {[\mathrm{J} / \mathrm{mol} . \mathrm{K}]}\end{array}$

\section{References}

Al-Mazaideh, G. M. "Carbohydrates as Green Corrosion Inhibitors of Copper Ab initio Study", Jord. J. Chem., 12, 189-200 (2017)

Al-Mazaideh, G. M., K. A. Abu-Sbeih, and Khalil S. M. "Computational calculations of chitosan fragments as corrosion inhibitors of metals", J. Chem., Biolo., Phy. Sci.,7, 398-409 (2017)

Al-Mazaideh, G. M., R. A. Enwisry and S. M. Khalil "Effect of substituents on methylenecyclo-butane /1-methylcyclobutene system", Inter. Res. J. Pure \& Appl. Chem., 12, 1-10 (2016)

Al-Mazaideh, G. M., and S. A. Al-Quran "Inhibitive action of Chamomile extract on the corrosion of Iron: Density Functional Theory", Mor. J. Chem., 6, 195-202 (2018)

Al-Mazaideh, G. M., T. S. Ababneh, K. H. Abu-Shandi, R. M. A. Q. Jamhour, H. J. Ayaal Salman, A. M. Al-Msiedeen and S. M. Khalil "DFT calculations of Mesembryanthemum nodiflorum compounds as corrosion inhibitors of aluminum", Phy. Sci. Inter. J., 12, 1-7 (2016)

Al-Mazaideh, G. M., W. B. Ejlidi and S. M. Khalil "A DFT study on stepwise fluorinated methylenecyclopentane and 1-methylcyclopentene system", Inter. Res. J. Pure \& Appl. Chem., 12, 1-14 (2016)

Al-Mazaideh, G. M., W. A. Al-Zereini, A. H. Al-Mustafa and S. M. Khalil "The effect of nitro maleimides from a marine vibrio species compounds as a source of environment-tally friendly corrosion inhibitors for metals: A computational study", Adv. Env. Biol., 10, 159-168 (2016)

Al-Msiedeen, A. M., G. M. Al-Mazaideh and S. M. Khalil "A theoretical study of the enol contents of cyclohexanone, cyclopentanone and acetone", Amer. Chem. Sci. $J ., 13,1-8(2016)$

El-Alali, A., A. A. Marashdeh and S. M. Khalil "A theoretical study of substituted stepwise fluorinated cyclopropenone keto-enol system", Z. Naturforsch., 58a,749$755(2003)$

Frisch, M.J., et al., Gaussian, Inc., Wallingford, CT, (2003).

Khalil, S. M. "A DFT study on the stepwise fluorinated methylenecyclopropane and 1-methylcyclo-propene system", Z. Naturforsch., 63a, 42-48 (2008)

Khalil, S. M., G. M. Al-Mazaideh and N. M. Ali "DFT calculations on corrosion inhibition of Aluminum by some carbohydrates", J. Biochem. Res. \& Rev., 14, 1-7 (2016)

Kubba, R. M., and F. K. Abood "DFT, PM3, AM1, and MINDO/3 quantum mechanical calculations for some INHC Cs symmetry schiff bases as corrosion inhibitors for Mild steel", Iraqi J. Sci., 56, 602-126 (2015)

Lindner, P. E. and D. M. Lemal "Energetics of fluoroalkene double bond isomerizations", J. Am. Chem. Soc., 119, 3267-3273 (1997)

Moradi, R., S. Jameh-Bozorghi, R. Kadivar, A. Mahdiani and H. Soleymanabadi "Study of mechanism keto-enol tautomerism (isomeric reaction) structure cyclohexanone by using Ab initio molecular orbital and density functional theory (DFT) method with NBO Analysis", APCBEE Procedia, 3, 70-74 (2012)

Smart, B. E., J. F. and A. Liebman "Molecular structure and energetic", 3, 141-191, Greenberg (eds.); VCH Publishers, Deerfield Beach, FL (1986)

Sway, M.I., I. D. M. Al-Shawabkeh and S. M. Khalil "A theoretical study of substituted cyclobuta-nones and their enols", Z. Naturforsch., 59, 838-844 (2004)

Wedian, F., M. A. Al-Qudaha and A. N Abu-Bakerb "The effect of capparis spinosa L.extract as a green inhibitor on the corrosion rate of copper in a strong alkaline solution", Portugaliae Electro-chimica Acta., 34,39-51 (2016) 